\section{Antihypertensive therapy with indapamide and perindopril reduced mortality in patients $\geqslant 80$ years}

\section{STUDY DESIGN}

Design: randomised placebo controlled trial (Hypertension in the Very Elderly Trial [HYVET]).

Allocation concealment: $\{\text { concealed }\}^{*} . \dagger$

Blinding: blinded (patients, clinicians, and outcome adjudication committee). $\dagger$

\section{STUDY QUESTION}

Setting: 195 centres in Europe, China, Australasia, and Tunisia.

Patients: 3845 patients $\geqslant 80$ years of age (mean age 84 y, $60 \%$ women) with persistent hypertension (mean sitting blood pressure $[\mathrm{BP}]$ 173/91 $\mathrm{mm} \mathrm{Hg}$ ). Exclusion criteria included accelerated or secondary hypertension, haemorrhagic stroke in the past 6 months, heart failure, gout, and dementia.

Intervention: sustained-release indapamide, $1.5 \mathrm{mg} /$ day, with perindopril, 2 or $4 \mathrm{mg} /$ day, added if needed to reach targets of systolic BP $<150 \mathrm{~mm} \mathrm{Hg}$ and diastolic BP $<80 \mathrm{~mm}$ $\mathrm{Hg}(\mathrm{n}=1933)$ or placebo $(\mathrm{n}=1912)$.

Outcomes: stroke, heart failure, any cardiovascular event, and death from any cause, cardiovascular cause, cardiac cause, or stroke.

Follow-up period: median 1.8 years.

Patient follow-up: 99.6\% (intention-to-treat analysis).

\section{MAIN RESULTS}

Antihypertensive treatment reduced risks of heart failure, any cardiovascular event, and death from stroke or any cause (table). At 2 years, target BP was achieved by $48 \%$ of the antihypertensive treatment group and $20 \%$ of the placebo group.

\section{CONCLUSION}

In patients $\geqslant 80$ years of age with persistent hypertension, antihypertensive therapy with indapamide and perindopril reduced all-cause mortality.

*Bulpitt C, Fletcher A, Beckett N, et al. Drugs Aging 2001;18:151-64.

†See glossary.

Abstract and commentary also appear in "ACP Journal Club: The Best Evidence for Patient Care" in Annals of Internal Medicine.

\section{ABSTRACTED FROM}

Beckett NS, Peters R, Fletcher AE, et al. Treatment of hypertension in patients 80 years of age or older. $N$ Engl J Med 2008;358:1887-98.

Correspondence to: Dr N S Beckett, Imperial College, London, UK; n.beckett@imperial.ac.uk

Source of funding: British Heart Foundation and Institut de Recherches Internationales Servier.

- Clinical Impact Ratings: Cardiology 7/7; GP/FP/Primary care 6/7; IM/Ambulatory care 6/7; Geriatrics 6/7

Antihypertensive therapy $v$ placebo in patients $\geqslant 80$ years of age with persistent hypertension*

\begin{tabular}{|c|c|c|c|c|}
\hline \multirow[b]{2}{*}{ Outcomes at median 1.8 years } & \multicolumn{2}{|c|}{ Rate per 1000 person-years } & \multirow[b]{2}{*}{ RRR $(95 \%$ Cl) } & \multirow[b]{2}{*}{ NNT (Cl) } \\
\hline & Antihypertensive & Placebo & & \\
\hline Stroke & 12 & 18 & $30 \%(-1$ to 51$)$ & Not significant \\
\hline Cardiovascular event $\dagger$ & 34 & 51 & $33 \%(18$ to 46$)$ & $60(43$ to 113$)$ \\
\hline Death from all causes & 47 & 60 & $20 \%$ (5 to 34$)$ & 82 (49 to 346 ) \\
\hline Death from stroke & 6.5 & 11 & $39 \%$ (1 to 62$)$ & 241 (151 to 9396$)$ \\
\hline
\end{tabular}

*Abbreviations defined in glossary. RRR, NNT, and $\mathrm{Cl}$ calculated from data in article.

$\dagger$ Stroke, myocardial infarction, heart failure, or death from cardiovascular cause.

$\mathrm{H}$ YVET found that antihypertensive treatment in the very old decreased mortality and the incidence of heart failure, with benefits seen within the first year. Although the reduction in some outcomes did not reach statistical significance, perhaps because the trial was stopped early, the results are impressive.

An earlier meta-analysis of randomised trials on the same topic found a decrease in stroke but not mortality. ${ }^{1}$ The HYVET authors speculated that the discrepancy in mortality results may be related to differences in treatment regimens, particularly the use of an angiotensin-converting enzyme inhibitor rather than a $\beta$-blocker. The finding of a mortality benefit needs to be replicated.

Of note, the target BP in HYVET and the trials included in the INDANA meta-analysis ${ }^{1}$ was higher than that recommended by current treatment guidelines. ${ }^{2}$ This disparity raises the question of whether additional value would be provided in this age group by further lowering BP beyond the target pressure of $150 / 80 \mathrm{~mm} \mathrm{Hg}$, especially considering that this approach may increase adverse effects.

An important question about HYVET is whether the results are generalisable to most elderly people. The study sample was a relatively healthy group with low prevalence of diabetes mellitus and coronary artery disease. Patients with heart failure or dementia and those requiring nursing care were excluded. The relative benefits and risks of treating frail elderly people with multiple comorbid conditions were not addressed by this trial and may never be known. However, because heart failure is the most common reason for hospital admission in this population and strokes can be life-altering events even to the very frail, antihypertensive treatment in moderation may be the best way to prevent these outcomes. Being 80 years of age or older should not preclude antihypertensive treatment.

William W Hung, MD, MPH Rosanne M Leipzig, MD, PhD

Mount Sinai Medical Center

New York, New York, USA

1. Gueyffier F, Bulpitt C, Boissel JP, et al. Antihypertensive drugs in very old people: a subgroup meta-analysis of randomised controlled trials. INDANA Group. Lancet 1999;353:793-6.

2. Chobanian AV, Bakris GL, Black HR, et al. Seventh report of the Joint National Committee on Prevention, Detection, Evaluation, and Treatment of High Blood Pressure. Hypertension 2003;42:1206-52. 